\title{
Home care patients in four Nordic capitals - predictors of nursing home admission during one-year followup
}

This article was published in the following Dove Press journal:

Journal of Multidisciplinary Healthcare

23 March 2010

Number of times this article has been viewed

\author{
Liv W Sørbye' \\ Torunn Hamran ${ }^{2}$ \\ Nils Henriksen ${ }^{2}$ \\ Astrid Norberg ${ }^{2,3}$ \\ 'Diakonhjemmet University College, \\ Oslo, Norway; ${ }^{2}$ Department \\ of Health and Care Sciences, Faculty \\ of Health Sciences, University of \\ Tromsø, Norway; ${ }^{3} U$ meå University, \\ Umeå, Ersta Sköndal University \\ College, Stockholm, Sweden
}

\begin{abstract}
The aim was to predict nursing home admission (NHA) for home care patients after a 12-month follow-up study. This Nordic study is derived from the aged in home care (AdHOC) project conducted in 2001-2003 with patients at 11 sites in Europe. The participants in the cohort study were randomly selected individuals, aged 65 years or older, receiving homecare in Oslo, Stockholm, Copenhagen, and Reykjavik. The Resident Assessment Instrument for Home Care (version 2.0) was used. Epidemiological and medical characteristics of patients and service utilization were recorded for 1508 home care patients (participation rate 74\%). In this sample $75 \%$ were female. The mean age was 82.1 (6.9) years for men and 84.0 (6.6) for women. The most consistent predictor of NHA was receiving skilled nursing procedures at baseline (help with medication and injections, administration or help with oxygen, intravenous, catheter and stoma care, wounds and skin care) (adjusted odds ratio $=3.7,95 \%$ confidence interval: $1.7-7.8$; $P<0.001)$. In this Nordic material, stronger emphasizing on higher qualified nurses in a home care setting could prevent or delay NHA.
\end{abstract}

Keywords: aged, home care, cross-sectional study, self-rated health, level of care, care burden, comprehensive assessment, RAI, Nordic

\section{Introduction}

In Nordic countries (here including Denmark, Iceland, Norway, and Sweden), as in many countries in continental Europe, adult children have no legal obligation to provide care or financial support for their elderly parents. ${ }^{1}$ In the Nordic countries, the formal health care systems have developed a more comprehensive home care service, than have many other European countries. ${ }^{2}$ They provide services to functionally impaired patients, including home help and home nursing, caregiver support and professional help related to rehabilitation. The distribution of home care is a question of local resources. Anyone may apply for health care, but it is the administrative staff in the municipalities that assess and determine the amount of help that will be given.

Many older people see their entitlement to public services as a right. ${ }^{3}$ Long-term care services are structured around the common belief that older people should live independently at home as long as possible. The threshold for an institutional bed in Norway, however, is low compared with other European countries. ${ }^{4}$

Few projects have compared the health status of home care patients between the Nordic countries. ${ }^{1}$ During the last decades there has been a change in the care of older people. Sweden has adjusted more than the other Nordic countries towards privatization of health care services. ${ }^{5}$ Comparative studies would be helpful to learn from best practice about the best care for older patients.
Correspondence: Liv Wergeland Sørbye Diakonhjemmet University, College, Adr. Postboks 184, 0319 Oslo, Norway Tel +4722 45। 978

Fax +472245 I 950

Email sorbye@diakonhjemmet.no 
A European Union study addressing social protection for the dependency elderly concluded that information is sparse regarding the needs of older individuals. The lack of a standardized gathering system precludes data collection and cross-national comparisons ${ }^{6}$ and a lack of data to identify home care patient or caregiver variables in predicting residential care utilization in local settings. ${ }^{7}$

A meta-analysis was conducted in the US of published research articles from 1950 to 2006, using the keywords "nursing home placement", "nursing home entry", "nursing home admission" (NHA), and "predictors of institutionalization" to identify predictors of NHA. Among the strongest predictors were dependencies in three or more activities of daily living (ADL) functions, cognitive impairment, and prior nursing home use. ${ }^{8}$ The current authors used the same keywords to search for relevant literature from April 2006 to May 2009, as supplemental to general methods. Common reasons for nursing home entry are deterioration of independence and mental confusion. ${ }^{9}$ Different models have been developed for predicting NHA. ${ }^{10-13}$ However, where elderly patients live after a given followup period is dependent on the availability of a nursing bed in the community and economical resources.

As a part of the Dutch Prevention of Influenza, Surveillance and Management (PRISMA) study, the perceived need for institutionalization was analyzed in a sample of old adults without cognitive impairment. Factors related to physical disabilities and inadequacy of resources were important correlates. ${ }^{14}$ Some older home care patients could probably manage better if they were moved to a more convenient environment, as the Swedish experience has shown. Over the last decade, Sweden has developed service houses and decreased the number of nursing home beds, while older patients in Iceland seem to prefer nursing home care. ${ }^{1}$

The aim of this study was to characterize home care patients and their need of assistance in the capitals of four Nordic countries, and determine predictors for NHA over a 12-month followup period.

\section{Material and methods}

This study is a spinoff project derived from the Aged in Home Care (AdHOC) project conducted in 2001-2003 in urban areas at 11 sites in Europe. This research uses data from four Nordic capitals: Oslo, Norway; Stockholm, Sweden; Copenhagen, Denmark and Reykjavik, Iceland (Data from Helsinki is excluded in this article because of lack of NHA data). The target study population was aged 65 years and over, and was already receiving home care services at the beginning of the study. The home care service in the Nordic capitals is divided into different sectors and consists of a network of services. A multidisciplinary team provides the patients with social service, personal care, nursing procedures, medical treatment, and rehabilitation.

A sample size of about 250 from each site allows $80 \%$ power to detect significant variations in the outcome variables over the study period. The national partners selected a random sample. The plan was that each site would have 405 participants. For practical reasons, the sample from each country varied from 246 in Stockholm to 469 in Copenhagen (Table 1). The percentage of people aged 65 years or more in the target study population was approximately equal to the national value for each site. ${ }^{15}$

Ethical approval for the study was obtained at all sites according to national regulations. Participants were assured of the confidentiality of study information and asked to give informed consent.

\section{Measurements}

Patients were assessed three times (at baseline, and after six and 12 months) using the inter $R A I$ version 2.0 Resident Assessment Instrument for Home Care (RAI-HC), which consists of over 300 items derived from the literature, where available (functional status, cognitive abilities, morbidity and symptoms, social contacts, communication, informal help, and sociodemographic background), and utilization of selected services and treatments. All items were assessed for each patient.

The RAI instrument has been translated, back-translated, and examined for validity in the language of each participating country. The instrument has good content and face validity, and good interobserver reliability. ${ }^{16,17}$

All assessments took place in the client's home. Assessors were trained to become familiar with the MDS and the entire RAI-HC. In some countries, the "normal staff” of home care agencies responsible for providing services was involved in data collection, usually with the assistance of special research nurses. The assessors were responsible for checking all the variables. If not applicable, "none of the above" was coded. Missing data were relatively rare.

\section{Definitions}

In analyzing the data from the Nordic capitals, we used alternative cutoff points for the total AdHOC sample, because the Nordic sample had a lighter case-mix than in other participating sites. When dichotomizing the scales, the 
Table I Background data, health service utilization and care burden stress in the participating sites

\begin{tabular}{|c|c|c|c|c|c|}
\hline & Copenhagen & Reykjavik & Oslo & Stockholm & Total \\
\hline & $n=469$ & $n=405$ & $\mathrm{n}=\mathbf{3 8 8}$ & $n=246$ & $n=1508$ \\
\hline Age $^{a}$ (years, mean, SD) & $84.4(6.8)$ & $81.7(6.6)$ & $83.9(6.3)$ & $84.1(6.8)$ & $83.5(6.7)$ \\
\hline Female & 79 & 74 & 72 & 73 & 75 \\
\hline Living alone & 76 & 68 & 74 & 80 & 74 \\
\hline Homebound ${ }^{b}$ & 28 & 22 & 28 & 24 & 27 \\
\hline Hospitalization in last 90 days & 13 & 13 & 13 & 14 & 13 \\
\hline Nursing procedures & 47 & 66 & 72 & 41 & 58 \\
\hline Nurse $^{c}$ (days per week, mean, SD) & $1.29(2.1)$ & $1.5(1.8)$ & $4.2(3.0)$ & $0.5(1.1)$ & $2.2(2.7)$ \\
\hline Care burden stress & 8 & 4 & 8 & 5 & 6 \\
\hline Better off somewhere else & 13 & 18 & 8 & 9 & 12 \\
\hline MAPLe ${ }^{d} \geq 4$ : high/very high priority $(0-5)$ & 15 & 16 & 16 & 12 & 15 \\
\hline Participations' rate & 90 & 97 & 93 & 62 & 74 \\
\hline Nursing home & 8 & 8 & 16 & 9 & 10 \\
\hline Dead & 10 & 6 & 17 & 23 & 13 \\
\hline
\end{tabular}

Notes: Data presented as percentage unless otherwise indicated. "Male $=82.1$ (6.9), Female $=84.0$ (6.6); "'No days out of the house or building during the last week" or "needed extensive assistance for outside locomotion". 'Visiting nurse $n=1026$; 'MAPLe (Method for Assigning Priority Levels) client's eligibility for admission to a nursing home (Scale 0-5).

Abbreviation: SD, standard deviation.

cutoff point was the value closest to the median. We used the ADL hierarchy scale for physical functioning; in which scores range from 0 to 8 with a cutoff point of $A D L \geq 1(56 \%$ of patients scored " 0 " [intact]). For instrumental activity, the instrumental activities of daily living (IADL) hierarchy scale was used; scores range from 0 to 7 with a cutoff point of IADL $\geq 4$ ( $49 \%$ were $<4)$. The Cognitive Performance Scale (CPS) measures the level of cognitive performance on a range from 0 to 6. A crosswalk between CPS and The Mini-Mental State Examination (MMSE) has been conducted..$^{18,19}$ The scale of the MMSE ranges from 30, indicating an absence of cognitive impairment, to 0 , indicating severe cognitive impairment, and a value between 6-0 corresponds to a score of $4-6$ on the CPS. A cutoff point of CPS $\geq 4$ was first chosen for clinically significant cognitive impairment, values that indicate moderate severe to very severe impairment. However, only 50 patients $(3.3 \%)$ met or exceeded this cutoff point. The cutoff point for the chi-square analysis and the regression model was set to CPS $\geq 1$. "Caregiver" is used here as a non-institutional person who provides care to a patient, ie, an informal caregiver. The two variables "care burden stress" and "better off living in another environment" were answered by the patients themselves or in collaboration with their caregiver. Care burden stress was coded as a positive response to any one of the following statements in the RAI-HC instrument: a) caregiver unable to continue; b) caregiver dissatisfied with support; or c) caregiver is experiencing distress. Whether the patient would be better off living in another environment was coded as a positive response from the patient, caregiver, or both.

The concept of "homebound" included a positive-coded response to one of the two following variables: "No days out of the house or building during the last week" or "Needed extensive assistance for outside locomotion".

With the exception of Reykjavik, the three other capitals offered integrated home care services, in which both social services and home nursing were administrated from the same office. In the RAI instrument, service providers were categorized in three groups, ie, visiting nurse, home health carer, and home help. One way to split home service and home nursing could be between IADL and ADL functions. To date, however, home service personnel may assist the patient with personal care, such as toileting, eating, and showering. This research focuses on variables in the RAI instrument, which are explicitly nursing-related. The following variables were dichotomized and recoded as nursing procedures: visiting nurse daily or less than daily in previous seven days, help with medication and injections, administration or help with oxygen, intravenous, catheter and stoma care, wounds, and skin care. Other variables included diagnoses, symptoms, falls, health conditions, incontinence (bladder or bowel), life expectancy, use of medications, and hospitalization. We used the MAPLe (Method for Assigning Priority Levels) algorithm ${ }^{20}$ to determine who should have been prioritized based on each characteristic. The algorithm uses 14 variables from the RAI-HC: ADL 
hierarchy scale, few meals, swallowing, behaviour, geriatric screener, ulcers (pressure/stasis), cognitive performance scale, institutional risk CAP, wandering, environment, meal preparation, worsening of decision-making, falls, and medication management.

\section{Statistical analysis}

Descriptive statistics were generated from baseline in 2001-2002 and from 12-month followup data, according to outcome variables. Statistical analyses were performed using SPSS software version 16. The results were assessed statistically using univariate, bivariate, and multivariate methods. The selection of variables was based upon theoretical considerations and experiences from other publications with the AdHOC data. ${ }^{15,21}$ Chi-square analysis for dichotomous variables was used to test characteristics and clinical features associated with NHA during the 12-month followup period.

Differences were considered statistically significant at a $P$ level below 0.05 . We used odds ratios (ORs) with $95 \%$ confidence intervals (CI) for risk estimates. A stepwise logistic regression model was developed using the variables in Table 2, except for two variables: the MAPLe algorithm which was excluded because it was created from a combination of several of the individual variables included in the regression and Parkinson's disease because of its low frequency $30(2 \%)$. The dependent variable was NHA during the 12-month followup period. A similar regression model was conducted separately for each capital.

\section{Results}

\section{Background data}

Table 1 presents general characteristics of the study sample ( $n=1508)$, of which $1129(74.9 \%)$ were women. The mean age (SD) was 83.5 (6.7) years; 82.1 (6.9) for men and 84.0 (6.6) for women.

The prevalence of use of nursing procedures among the population varied across countries, ranging from $41 \%$ to $72 \%$ (Table 1). On average, $74 \%$ of the people in the sample lived alone and $27 \%$ were assessed as being homebound. Of those patients who received nursing procedures, the number of days of visiting nurse service in the previous week varied from 4.2 (3.0) days in Oslo to 0.5 (1.1) days in Stockholm. Overall, 185 $(12.3 \%)$ of patients or informal caregivers assessed the elderly patient to be better off living in another environment (patients $4.2 \%$, caregiver $3.5 \%$, and patient and caregiver $4.6 \%$ ).

Using the MAPLe algorithm, 220 (15\%) of the recipients were determined to be a high or very high priority for admission to a nursing home. After 12 months, 153 recipients (10\%) had moved to a nursing home, while 198 (13\%) had died. Of those who died during the study period, 20 had moved to a nursing home prior to their death (11 participants in Oslo, eight in Stockholm and one from Reykjavik).

MAPLe provided an estimated risk for NHA $(\mathrm{OR}=2.29$, 95\% CI: 2.00-4.27), $P<0.001$. Self-rated bad health was statistically significant for NHA $(\mathrm{OR}=1.56,95 \%$ CI: 1.11-2.19).

\section{Predictive factors of NHA}

The logistic regression model for the whole sample gave an explanatory value of $25 \%$ (Table 3 ). Predictors remaining in the final stepwise model were nursing procedures, IADL $\geq 4$, better off living in another environment, homebound, age $85+$, CPS $\geq 1$, and incontinent (bowel or bladder). The strongest predictor in Norway and Reykjavik was nursing procedures, and IADL $\geq 4$ for Copenhagen and Stockholm.

\section{Discussion}

Qualified documentation of the patient's health status is a sign of professionalism for both nurses and physicians. It is necessary to ensure continuity of care and effective treatment of the patient. ${ }^{22}$ Several authors have emphasized the need for more cross-national studies to assess comprehensively the health-related needs of older populations. Legal and economic rights have dominated projects related to research concerning Scandinavian welfare policy, and less focus has been on services and practical aspects of home care. ${ }^{23}$ A review of the Nordic Council's report on research on the care of the elderly concluded that more health data are needed. ${ }^{24}$ As far as we know, ours is the first study that compares home care in the Nordic capitals using a standardized comprehensive geriatric assessment instrument.

Several common characteristics of home care participants at each site and across Nordic populations were observed. Approximately $15 \%$ of the population in each site were over the age of 65 years (with the exception of Stockholm, which had a higher percentage of over 65 year olds). This prevalence is very close to that of national population in each country. The frequency of older women living alone in the Nordic sites was high compared with other European sites. ${ }^{15,25}$ Because of their old-age pension, the Nordic welfare model keeps elderly females economically independent. In the analysis of the OASIS project that included five European countries (Norway, United Kingdom, Germany, Spain, and Israel), it was found that with respect to issues such as whether adult children 
Table 2 Characteristics and clinical features associated with nursing home admission during the 12-month followup

\begin{tabular}{|c|c|c|c|c|c|}
\hline \multirow[t]{2}{*}{ Yes/No } & \multirow[t]{2}{*}{ Overall n (\%) } & \multicolumn{2}{|l|}{ NHA } & \multirow[t]{2}{*}{$P$-value } & \multirow{2}{*}{$\begin{array}{l}\text { Odds ratio } \\
\text { ( } 95 \% \text { confidence } \\
\text { intervals) }\end{array}$} \\
\hline & & Yes n (\%) & No $n(\%)$ & & \\
\hline \multicolumn{6}{|c|}{ Demographic characteristics of patients } \\
\hline Female & $1129(74.9)$ & $113(10.0)$ & $1016(90.0)$ & 0.761 & $0.94(0.64-1.38)$ \\
\hline Male & $379(25.1)$ & $40(10.6)$ & $339(89.4)$ & 0.761 & $1.06(0.75-1.55)$ \\
\hline Age 85 years and over & $662(43.9)$ & $88(13.3)$ & $574(86.7)$ & 0.001 & $1.84(1.31-2.58)$ \\
\hline Lived alone & 1115 (73.9) & $103(9.2)$ & $1012(90.8)$ & 0.05 & $0.70(0.48-1.00)$ \\
\hline \multicolumn{6}{|l|}{ Diagnosis } \\
\hline Alzheimer's/dementia & $174(|| .5)$ & $28(16.1)$ & I $46(83.9)$ & 0.006 & $1.86(1.19-2.89)$ \\
\hline Parkinson's disease & $30(2.0)$ & $10(33.3)$ & $20(66.7)$ & 0.001 & $4.67(2.14-10.17)$ \\
\hline Arthritis & $492(32.6)$ & $64(13.0)$ & $428(87.0)$ & 0.01 & $1.56(1.11-2.19)$ \\
\hline \multicolumn{6}{|l|}{$\begin{array}{l}\text { Symptoms and need } \\
\text { of assistance }\end{array}$} \\
\hline CPS scale $\geq 1(0-6)$ & $484(32.1)$ & $91(18.8)$ & $393(81.2)$ & 0.001 & $3.59(2.55-5.07)$ \\
\hline CPS scale $\geq 4(0-6)$ & $50(3.3)$ & $16(32.0)$ & $34(68.0)$ & 0.001 & $4.54(2.54-8.43)$ \\
\hline Unstable condition $^{\mathrm{a}}$ & $244(16.2)$ & $46(18.9)$ & I98 (8I.I) & 0.01 & $2.51(1.72-3.66)$ \\
\hline ADL scale $\geq I(0-8)$ & $637(42.3)$ & $98(15.4)$ & $539(84.6)$ & 0.001 & $2.69(1.90-3.81)$ \\
\hline IADL scale $\geq 4(0-7)$ & $751(49.8)$ & $128(17.0)$ & $623(83.0)$ & 0.001 & $6.02(3.87-9.36)$ \\
\hline MAPLe $^{\text {b }}$ scale $\geq 4(0-5)$ & $220(14.6)$ & $46(20.9)$ & I74 (79.1) & 0.001 & $2.29(2.00-4.27)$ \\
\hline Dizziness & $372(24.7)$ & $51(13.7)$ & $321(86.3)$ & 0.009 & $1.61(1.13-2.31)$ \\
\hline Falls (last 90 days) & $342(22.7)$ & $52(15.2)$ & $291(84.8)$ & 0.001 & $\mathrm{I} .88(\mathrm{I} .3 \mathrm{I}-2.70)$ \\
\hline Vision/hearing problems & $620(4 I . I)$ & $103(16.6)$ & $517(83.4)$ & 0.001 & $3.34(2.34-4.76)$ \\
\hline Incontinence ${ }^{c}$ & $638(42.3)$ & $92(14.4)$ & $546(85.6)$ & 0.001 & $2.24(1.59-3.14)$ \\
\hline \multicolumn{6}{|l|}{ Medications } \\
\hline Antidepressants & $305(20.3)$ & $46(15.1)$ & $259(84.9)$ & 0.001 & $1.83(1.26-2.66)$ \\
\hline \multicolumn{6}{|l|}{ Health status } \\
\hline Self-rated bad health & $492(32.6)$ & $64(13.0)$ & $428(87.0)$ & 0.01 & $1.56(1.11-2.19)$ \\
\hline Homebound & $390(25.9)$ & $74(19.0)$ & $316(81.0)$ & 0.001 & $3.08(2.19-3.33)$ \\
\hline Better off in another environment & $185(12.3)$ & $44(23.8)$ & I4I (76.2) & 0.001 & $3.48(2.35-5.14)$ \\
\hline \multicolumn{6}{|l|}{ Formal and informal care } \\
\hline Nursing procedures & $867(57.5)$ & $130(15.0)$ & $737(85.0)$ & 0.001 & $4.74(3.00-7.48)$ \\
\hline Hospitalized last 90 days & $200(13.3)$ & $32(16.0)$ & $168(84.0)$ & 0.003 & $1.87(1.23-2.85)$ \\
\hline Prior LTCF & $106(7.0)$ & $23(21.7)$ & $83(78.3)$ & 0.001 & $2.71(1.65-4.45)$ \\
\hline Caregiver stress & $99(14.4)$ & $21(21.2)$ & $78(78.8)$ & 0.014 & $4.96(2.14-3.37)$ \\
\hline \multicolumn{6}{|l|}{ Country-specific site } \\
\hline Copenhagen & $469(31.1)$ & $38(8.1)$ & 431 (9l.9) & 0.077 & $0.71(0.48-1.04)$ \\
\hline Reykjavik & $405(26.9)$ & $32(7.9)$ & $373(92.1)$ & 0.080 & $0.70(0.46-1.46)$ \\
\hline Oslo & $388(25.7)$ & $62(16.0)$ & $326(84.0)$ & 0.001 & $2.15(1.52-3.04)$ \\
\hline Stockholm & $246(16.3)$ & $2 \mathrm{I}(8.7)$ & $225(9 \mid .5)$ & 0.361 & $0.80(0.49-1.29)$ \\
\hline
\end{tabular}

Notes: aHas conditions or diseases that make cognition, ADL, mood or behaviour patterns unstable (fluctuations, precarious, or deteriorating; ${ }^{b}$ MAPLe) client's eligibility for admission to a (Scale 0-5); 'Bowel or bladder.

Abbreviations: ADL, activities of daily living; CPS, Cognitive Performance Scale; IADL, instrumental activities of daily living; LTCF, long time care facility; MAPLe, Method for Assigning Priority Levels.

should live close to their parents, Norwegians subscribed to a norm of independent living. ${ }^{4,26}$ Older Norwegians preferred residential living to living with their children, and this preference was highest among the oldest age group
(75+ years). Norwegians were more likely than other European participants to place primary responsibility for care of the elderly on the welfare state. We anticipate that there would be the same tendency in the other Nordic 
Table 3 Binary logistic regression analysis with forward selection of variables: Nursing home admission during the 12-month followup

\begin{tabular}{llll}
\hline Independent variable & $\begin{array}{l}\text { Adjusted } \\
\text { odds ratio }\end{array}$ & $\mathbf{9 5 \% ~ C l ~}$ & P-value \\
\hline Aged $\geq 85$ & 1.73 & $1.06-2.80$ & 0.029 \\
IADL $\geq 4$ (scale 0-7) & 2.25 & $1.18-4.28$ & 0.014 \\
CPS $\geq$ I (scale 0-6) & 1.68 & $1.01-2.80$ & 0.046 \\
Nursing procedures & 3.67 & $1.72-7.82$ & 0.001 \\
Homebound & 1.80 & $1.08-2.99$ & 0.023 \\
Incontinent (bowel/bladder) & 1.67 & $1.03-2.72$ & 0.040 \\
$\begin{array}{l}\text { Better off in another } \\
\text { environment }\end{array}$ & 2.09 & $1.11-3.93$ & 0.022 \\
\hline
\end{tabular}

Notes: Wald $\chi^{2}(7)=81,640 ; P, 0.001$; Nagelkerke $R^{2}=0.25$.

Abbreviations: $\mathrm{Cl}$, confidence interval; $\mathrm{CPS}$, ; IADL, .

countries. The AdHOC data revealed that the recipients of home care in the Nordic capitals appeared to be generally less dependent than those cared for in other sites, and that these recipients had lower levels of ADL and cognitive impairment. ${ }^{15}$ Examination of service delivery in the AdHOC sample revealed that the Nordic capitals' and Amsterdam's management mainly provided assistance for ADL and basic nursing care according a sociomedical model (both social and medical services were provided for the home care population) while other sites had less integrated models. ${ }^{21}$ In the Nordic sites, older patients with a CPS $\geq 4$ seldom remained at home $50(3.3 \%)$. They would be offered a bed in an institution if the next of kin were unable to provide care, a trend that was rare in the southern part of Europe..$^{15}$

Data from a 12-month followup assessment enabled us to identify predictors for NHA. Several models have been developed for studying the risk associated with NHA. A model was developed for a population study over the age of 70 years in Iowa. This model includes demographic and social factors, as well as self-reported attitudes, beliefs, and expectations for NHA. Older age, prior hospitalization or nursing home use, lower self-rated health, and difficulties with ADL or IADL were also statistically significant and strong risk factors for NHA. ${ }^{11}$ A qualitative study of psychosocial factors concerning NHA was conducted with participants in 12 American focus groups. All participants had previous personal experience with health care services, either as a patient or as a caregiver. The most common factors influencing long-term care decision-making were family care burden and care-giving expectations, ${ }^{10}$ which is consistent with our results and those of other studies. Caregiver stressors in conjunction with care recipient characteristics are important for predicting NHA for persons with dementia-related diseases in particular. ${ }^{27}$

International RAI-HC data from earlier studies were used to identify predictors for nursing home placement, caregiver distress, and for being rated as requiring alternative placement to improve outlook. Iceland and Sweden were similar in that the majority of home care clients were skewed toward the low, mild, and moderate MAPLe priority levels compared with data from the US, Italy, and Japan. As in our Nordic study, it was found that being assessed to be better off living in another environment was a statistically significant predictor for NHA. ${ }^{12}$

Self-rated health at baseline is an approved predictor for future illness and mortality. ${ }^{28}$ In our Nordic study of older patients, 492 (32.6\%) rated their health as bad. Sixty-four (13\%) got a nursing home bed during the 12-month followup period. Bad health is often automatically associated with old age, and important clinical markers may be underreported. The strongest predictor of NHA in the Nordic study was receiving nursing procedures (adjusted $\mathrm{OR}=3.7,95 \%$ confidence interval [CI]: 1.7-7.8; chi-square $P<0.001$ ). As far as we know, this predictor has not been used in similar models before. When a patient is in need of skilled nursing over time, the threshold for getting a nursing home bed has been rather low. Skilled nurses determine the extent of the recipient's needs. Older patients discharged after an acute hospitalization are at high risk for institutionalization. ${ }^{29}$ Researchers suggest use of administrative claims for identifying NHAs, together with various clinical and organizational approaches for prevention of NHA. ${ }^{13,21,30}$

Older patients living in Oslo had greater access to a nursing home than do their counterparts in the other Nordic sites. We have yet to determine an explanation for the higher frequency of recipients (21\%) in Reykjavik regarded as being better off living in another environment. Iceland has had the highest frequency of nursing home beds $(9.1$ beds per 100 individuals over the age of 65 years) compared with Denmark, for example, which has three beds per 100 individuals over the age of 65 years. ${ }^{1}$ One explanation for this disparity may be that attitudes toward living in a nursing home are more positive in Reykjavik than in other sites.

In Copenhagen and Stockholm, multiple impairments in IADL functions were a stronger predictor of NHA than nursing procedures. A probable explanation could be that these two capitals had more qualified nurses than the other capitals, but were short of staff in other respects.

Home care has undergone considerable changes in recent years as a result of reimbursement policies, access, and 
utilization, leading to uncertainty about focus and goals for the care of the recipients. ${ }^{31}$ In the Nordic countries, we have seen that municipal authorities are no longer the sole providers of care for senior citizens, and several private agencies have now entered the market. These changes increase the demand for control and quality assurance. Researchers have emphasized the need for assessment dialogues to mediate activities serving a fundamental function of bridging institutional, professional, individual, and personal perspectives. ${ }^{32}$ Our experiences from the AdHOC study support this view. ${ }^{33}$

The aim of assessment using the RAI instrument was to capture the minimum information needed when assessing a frail and elderly patient. The strengths of this study were the large sample size and the use of a standardized assessment tool cross-nationally in a home-service setting.

One of the limitations of our study is that the data were gathered from home care units in one area of the capital in each of the participating countries, thus we cannot conclusively determine whether the variations reflect differences between specific sites or entire countries. Futhermore, we do not have information about older people who are not receiving home care.

Despite its wide use, dichotomization of independent continuous variables has been criticised for potential loss of information about individual differences, loss of effect size and power, and biased parameter estimates. ${ }^{34,35}$ The simplification gained through dichotomization may thus represent a weakness in our study. Use of stepwise regression is also subject to criticism for possibly overfitting the model, making replication of results difficult because of the random selection of parameters in the sample at hand based upon purely mathematical rather than theoretical grounds. ${ }^{36,37}$ The initial selection of variables was based upon theoretical considerations, although the subsequent use of stepwise methods may introduce a weakness. As this study was not designed to investigate whether participants required institutional care, the power of the sample was not originally calculated for this analysis. The highly reduced set of variables embedded in the RAI assessment form limit the ability of the study to measure a patients' view of his or her situation.

\section{Conclusion}

In this Nordic sample, community home care, on average, was not provided to patients with severe functional impairment as in other European sites. Nordic home care patients were vulnerable because of living by themselves. The strongest overall predictor of NHA was receiving skilled nursing procedures. A stronger emphasis on highly qualified nurses and non-medical staff could prevent or delay NHA. Home care recipients in Oslo were more frequently moved to a nursing home during our 12-month followup period, in contrast with Reykjavik, where a higher proportion compared with baseline was assessed to being better off living in another environment. The relationship between the common features of these Nordic home care populations and their welfare states warrants further investigation. European countries like Germany, France, and Italy may extend their community care. The housing policy for older people in the Nordic countries may be stimulated to develop more collective living arrangements, including within the families.

\section{Acknowledgements}

We are grateful to the following Nordic interRAI fellows: Palmi V Jónnson, Harriet Finne-Soveri, Marianne Schroll, and Gunnar Ljunggren, and to the AdHOC collaborators represented by Roberto Bernabei. The AdHOC study is founded by the European Commission Fifth Framework Program, contract number QLRT-2000-00002 and the Norwegian Medical Association.

\section{Disclosure}

The author reports no conflicts of interest in this work.

\section{References}

1. Szebehely M. Äldreomsorgsforskning i Norden. En kunskapsöversikt. (Care of elderly people. An overview of research.) København: Nordisk råd (Nordic council); 2005 cited. Available from: http://www.norden. org/pub/velfaerd/social_helse/sk/TN2005508.pdf. Accessed Feb 18, 2010. Norwegian.

2. Tarricone R. AD home care in Europe: The solid facts. Luigi Bocconi: Università Commerciale Luigi Boccon. 2008. Available from: http:// www.euro.who.int/Document/E91884.pdf. Accessed Feb 18, Accessed Feb 18, 2010.

3. Lin K. Sectors, agents and rationale. A study of the Scandinavian welfare states with special reference to the welfare society model. Acta Sociol. 2004;47(2):41-157.

4. Daatland SO, Herlofson K. Norms and ideals about elder care in a European comparative perspective. In: Lowenstein A, Ogg J, editors. OASIS Final Report. Haifa Israel: Centre for Research and Study of Aging, University of Haifa: 2003:127-164.

5. Sundström G, Johansson L. The changing balance of government and family in care for the elderly in Sweden and other European countries. Australas J Ageing. 2005;(24):S5-S11.

6. Pacolet J, Bouten R, Lanoye H, Versieck K, (editors). Social Protection for Dependency in Old Age. A Study of the Fifteen EU members'states and Norway. Aldershot: Ashgate Publishing; 2000.

7. Larsson K, Thorslund M, Forsell Y. Dementia and depressive symptoms as predictors of home help utilization among the oldest old: Population-based study in an urban area of Sweden. J Aging Health. 2004 Nov;16(5):641-668.

8. Gaugler JE, Duval S, Anderson KA, Kane RL. Predicting nursing home admission in the US: A meta-analysis. BMC Geriatr. 2007;7:13. 
9. Cohen-Mansfield J, Wirtz P. The reasons for nursing home entry in an adult day care population: Caregiver reports versus regression results. J Geriatr Psychiatry Neurol. 22(4):274-281.

10. Bradley EH, McGraw SA, Curry L, et al. Expanding the Andersen model: The role of psychosocial factors in long-term care use. Health Serv Res. 2002;37(5):1221-1242.

11. Akamigbo AB, Wolinsky FD. Reported expectations for nursing home placement among older adults and their role as risk factors for nursing home admissions. Gerontologist. 2006;46(4):464-473.

12. Hirdes J, Poss J, Curtin-Telegdi N. The method for assigning priority levels (MAPLe): A new decision-support system for allocating home care resources. BMC Med. 2008;6:9.

13. Zuckerman IH, Sato M, Hsu VD, Hernandez JJ. Validation of a method for identifying nursing home admissions using administrative claims. BMC Health Serv Res. 2007;7:202.

14. Dubois MF, Dubuc N, Raiche M, Caron CD, Hebert R. Correlates of the perceived need for institutionalisation among older adults without cognitive impairment. Gerontology. 2008;54(4):244-251.

15. Carpenter I, Gambassi G, Topinkova E, et al. Community care in Europe. The aged in home care project (AdHOC). Aging Clin Exp Res. 2004;16(4):259-269.

16. Morris J, Fries B, Steel K, et al. Comprehensive clinical assessment in community setting: Applicability of the MDS HC. J Am Geriatr Soc. 1997;45(8):1017-1024.

17. Landi F, Onder G, Tua E, et al. Impact of a new assessment system, the MDS-HC, on function and hospitalization of home bound elderly: A controlled clinical trial. Silvernet-HC Study Group of Bergamo. J Am Geriatr Soc. 2000;49(10):1288-1293.

18. Morris JN, Fries BE, Mehr DR, et al. The MDS cognitive performance scale. J Gerontol. 1994;49(4):174-182.

19. Hartmaier SL, Sloane PD, Guess HA, Koch GG, Mitchell CM, Phillips CD. Validation of the minimum data set cognitive performance scale: Agreement with the mini-mental state examination. J Gerontol A Biol Sci Med Sci. 1995;50(2):M128-M133.

20. Ontario. Maple Journal. 2003. Available from: http://www.health. gov.on.ca/english/providers/program/ltc_redev/ccacltc/education/ fact_sheets/factsheet11.pdf. Accessed Feb 18, 2010.

21. Henrard JC, Ankri J, Frijters D, et al. Proposal of a service delivery integration index of home care for older persons: application in several European cities. Int J Integr Care. 2006;6:e11.

22. Landi F, Onder G, Tua E, et al. Impact of a new assessment system, the MDS-HC, on function and hospitalization of homebound older people: A controlled clinical trial. J Am Geriatr Soc. 2001;49(10): 1288-1293.
23. Hamran T. Kvinneforeningene, institusjonsbyggingen og den nasjonale velferdspolitikken. Nord-Norge før 1940 (Women's associations, establishment of institutions and national welfare policy. Northern Norway prior to 1940). Hist Tidsskr. 2007;86(3):411-430.

24. Romøren TI. Äldreomsorgsforskning i Norden. En kunskapsöversikt. Tidsskrift for velferdsforskning. 2006;9(2):122-123.

25. Fletcher AE, Price GM, Ng ES, et al. Population-based multidimensional assessment of older people in UK general practice: A cluster-randomised factorial trial. Lancet. 2004;364(9446):1667-1677.

26. Daatland SO, Herlofson K, editors. Ageing, Intergenerational Relations, Care Systems and Quality of Life - an Introduction to the OASIS Project Oslo, Norway: NOVA: 14; 2001.

27. Gaugler JE, Yu F, Krichbaum K, Wyman JF. Predictors of nursing home admission for persons with dementia. Med Care. 2009;47(2): 191-198.

28. Nielsen AB, Siersma V, Hiort LC, Drivsholm T, Kreiner S, Hollnagel H. Self-rated general health among 40-year-old Danes and its association with all-cause mortality at 10, 20, and 29 years' followup. Scand J Public Health. 2008;36(1):3-11.

29. Gill TM, Gahbauer EA, Han L, Allore HG. Functional trajectories in older persons admitted to a nursing home with disability after an acute hospitalization. J Am Geriatr Soc. 2009;57(2):195-201.

30. Bellelli G, Magnifico F, Trabucchi M. Outcomes at 12 months in a population of elderly patients discharged from a rehabilitation unit. J Am Med Dir Assoc. 2008;9(1):55-64.

31. Porter E. Older widows' experience of home care. Nurs Res. 2005;54(5):296-303.

32. Hellström Muhli UH. Att Överbrygga Perspektiv en Studie av Behovsbedömningssamtal Inom Äldreinriktat Socialt Arbete. Göteborg, Sweden: Acta Universitatis Gothoburgensis; 2003.

33. Sorbye LW, Garms-Homolova V, Henrard JC, et al. Shaping home care in Europe: The contribution of the aged in home care project. Maturitas. 2009;62(3):235-242.

34. McCallum J, Simons LA, Simons J, Friedlander Y. Delaying dementia and nursing home placement: the Dubbo study of elderly Australians over a 14-year follow-up. Ann N Y Acad Sci. 2007;1114:121-129.

35. Royston P, Altman DG, Sauerbrei W. Dichotomizing continuous predictors in multiple regression: a bad idea. Stat Med. 2006;25(1): $127-141$.

36. Babyak MA. What you see may not be what you get: A brief, nontechnical introduction to overfitting in regression-type models. Psychosom Med. 2004;66(3):411-421.

37. Field A. Discovering Statistics Using SPSS. London, UK: Sage; 2005.
Journal of Multidisciplinary Healthcare

\section{Publish your work in this journal}

The Journal of Multidisciplinary Healthcare is an international, peerreviewed open-access journal that aims to represent and publish research in healthcare areas delivered by practitioners of different disciplines. This includes studies and reviews conducted by multidisciplinary teams as well as research which evaluates the results or conduct of such teams or

\section{Dovepress}

healthcare processes in general. The journal covers a wide range of areas and welcomes submission from practitioners at all levels, from all over the world. The manuscript management system is completely online and includes a very quick and fair peer-review system. Visit http://www.dovepress.com/testimonials.php to read real quotes from published authors. 